\title{
Meta-Analysis of Aldehyde Dehydrogenase 2 Gene Polymorphism and Alzheimer's Disease in East Asians
}

\author{
Pan-Pan Hao, Yu-Guo Chen, Jia-Li Wang, Xing Li Wang, Yun Zhang
}

\begin{abstract}
Background: The association of genetic polymorphism of mitochondrial aldehyde dehydrogenase $2(A L D H 2)$ and Alzheimer's disease (AD) has been controversial and has been investigated only in several small-sample studies. In the present study, we performed a meta-analysis to evaluate the cross-sectional association of $A L D H 2$ variants and AD risk in East Asian populations. Methods: Trials were retrieved through MEDLINE, EMBASE, J-STAGE and the China National Knowledge Internet databases (from January 1, 1994 to November 1, 2010) without any restriction on language. Data were abstracted by a standardized protocol. Results: We found four studies of $821 \mathrm{AD}$ patients and 1380 healthy controls that qualified for the analysis. The variant $A L D H 2$ genotype GA/AA was not associated with increased $\mathrm{AD}$ risk (odds ratio $(\mathrm{OR})=1.35 ; 95 \%$ confidence interval $(\mathrm{CI})=0.75-2.42 ; \mathrm{p}=0.32$ ), even after stratification for the status of apolipoprotein E epsilon 4 allele. However, in the subgroup analyses, the association was significant for men $(\mathrm{OR}=1.72 ; 95 \% \mathrm{CI}=1.10-2.67 ; \mathrm{p}=0.02)$. Conclusions: This study adds to the evidence that $A L D H 2 \mathrm{GA} / \mathrm{AA}$ genotype increases the risk of $\mathrm{AD}$ among East Asian men, although the effect size is moderate.
\end{abstract}

RÉSUMÉ: Meta-analyse portant sur la relation entre le polymorphisme du gène ALDH2 et la maladie d'Alzheimer chez des populations de l'Asie de l'Est. Contexte : L'association entre le polymorphisme du gène de l'aldéhyde déshydrogénase 2 (ALDH2) et la maladie d'Alzheimer (MA) est controversée et elle a été examinée seulement au cours d'études faites chez un petit nombre de sujets. Nous avons effectué une méta-analyse pour évaluer l'association transversale de variations dans le gène de l'ALDH2 et le risque de MA dans des populations de l'Asie de l'Est. Méthode : Nous avons identifié les études dans MEDLINE, EMBASE, J-STAGE et dans les bases de données de China National Knowledge Internet, du 1er janvier 1994 au 1er novembre 2010, sans restriction quant à la langue de publication. Les données ont été recueillies selon un protocole standardisé. Résultats : Nous avons identifié 4 études portant sur un total de 821 patients atteints de MA et 1380 témoins en bonne santé, qui rencontraient les critères établis pour l'analyse. La variante génotypique GA/AA du gène de l'ALDH2 n'était pas associée à un risque accru de MA (RC = 1,35; IC à 95\% : 0,75 à 2,42; $\mathrm{p}=0,32)$, même après ajustement pour la présence de l'allèle epsilon 4 du gène de l'apolipoprotéine E. Cependant, dans les analyses de sous-groupes, l'association était significative chez les hommes ( $\mathrm{RC}=1,72$; IC à $95 \%: 1,10$ à 2,67; p = 0,02). Conclusions : Cette étude appuie la notion que le génotype GA/AA du gène de l'ALDH2 augmente le risque de MA chez les hommes de l'Asie de l'Est, mais que cet effet est modéré.

Can. J. Neurol. Sci. 2011; 38: 500-506

Alzheimer's disease (AD) is an irreversible, progressive neurodegenerative disease. It has been proved that apolipoprotein E epsilon 4 allele (APOE \&4) is associated with increased susceptibility to AD. ${ }^{1,2}$ However, the cause of AD has not been fully elucidated. The discovery of additional genetic factors is needed for clinical diagnoses and therapy of AD.

Mitochondrial acetaldehyde dehydrogenase 2 (ALDH2), a polymorphic enzyme responsible for the oxidation of acetaldehyde to acetate, is encoded by the $A L D H 2$ gene on chromosome 12. The $A L D H 2$ gene is composed of 13 exons. Exon 12 contains a G-to-A missense mutation resulting in a substitution of lysine for glutamic acid at amino acid position 504 of $A L D H 2$ (known as Glu504Lys). Hence, two ALDH2 alleles encode the active and inactive subunits (Glu504 and Lys504, also called $A L D H 2 * 1$ and $A L D H 2 * 2$, respectively) and three combinations, namely, $* 1 / * 1$ (wide-type homozygote), $* 1 / * 2$ (heterozygote) and $* 2 / * 2$ (mutant homozygote). The $A L D H 2 * 2$ allele is associated with reduced ALDH2 activity and thus, with an accumulation of acetaldehyde and 4-hydroxy-2- nonenal (HNE), which have been proposed to be potentially linked with $\mathrm{AD} .^{3-5}$ Therefore $A L D H 2 * 2$ could have a role in the pathogenesis of AD. This hypothesis is important to genetic research into $\mathrm{AD}$, especially in East Asian populations, because the $A L D H 2 * 2$ allele is rare in Caucasians (lower than $5 \%$ ) but is widely prevalent among East Asians (30\%-50\%). ${ }^{6,7}$

From the Key Laboratory of Cardiovascular Remodeling and Function Research, Chinese Ministry of Education and Chinese Ministry of Public Health (PPH, YGC, JLW, YZ), Qilu Hospital, Shandong University, Jinan, China; Division of Cardiothoracic Surgery, The Michael E. DeBakey Department of Surgery (XLW), Baylor College of Medicine, Houston, Texas, USA.

Received September 23, 2010. Final Revisions Submitted November 22, 2010. Correspondence to: Yun Zhang or Yu-Guo Chen, Key Laboratory of Cardiovascular Remodeling and Function Research, Chinese Ministry of Education and Chinese Ministry of Public Health, Qilu Hospital, Shandong University, No. 107, Wen Hua Xi Road, Jinan 250012, China. Pan-Pan Hao and Jia-Li contributed to this work equally. 
Although results from two Western studies suggest that increased ALDH activity might be a protective response of cerebral cortex and putamen to AD by detoxifying acetaldehyde and $\mathrm{HNE}, 5,8$ no investigation of the association of $A L D H 2$ gene polymorphism with $\mathrm{AD}$ in non-Asian populations, in which the $A L D H 2 * 2$ allele is rare, has been reported until now. Two casecontrol studies ${ }^{9,10}$ found that $A L D H 2$ gene polymorphism might be a risk factor for $\mathrm{AD}$ and be dependent on $A P O E \varepsilon 4$ status in East Asian populations. However, several other studies ${ }^{11-13}$ did not obtain the same results. The reason for the discrepancy is unclear but may be related to low statistical power or to differences in APOE $\& 4$ status. Thus, we conducted a metaanalysis to investigate the possible association of $A L D H 2$ genetic variation and $\mathrm{AD}$ in East Asian populations. Meta-analysis is a commonly used analytical tool to answer clinical questions that are not addressed by individual studies; its advantages include increased statistical power, large sample size, wide population coverage, and cost-effectiveness.

\section{METHODS}

\section{Selection criteria}

Studies were included in the meta-analysis if they (i) investigated the association of ALDH2 Glu504Lys polymorphism and $\mathrm{AD}$ risk in an East Asian population; (ii) were retrospective or nested case-control studies of a hospital- or population-based design; and (iii) contained sufficient information for genotype counts for estimating the odds ratio (OR) and its corresponding 95\% confidence interval (CI). Studies not meeting these criteria, animal studies, and studies without sufficient data were excluded from the analysis. When two papers reported the same study, only one publication with more complete and recent data was included in the analysis.

\section{Search source and strategy}

Publications were identified via the search engines of MEDLINE, EMBASE, J-STAGE and the China National Knowledge Internet databases (from January 1, 1994 to November 1, 2010) without any restriction on language. The following keywords were used for search: ((aldehyde dehydrogenase 2) OR (ALDH2)) AND ((Alzheimer's disease), OR (AD), OR (dementia)). The reference lists of all retrieved articles were checked for other relevant publications, and studies not included in the four databases were searched manually. The authors of the identified papers and relevant specialists were contacted for additional information.

\section{Data management}

The following information was extracted using a standardized protocol and reporting form: first author's last name, year of publication, number of subjects in each category, counts of subjects with different genotypes among $\mathrm{AD}$ patients and controls, clinical characteristics of each study population, study design, and ethnicity of the population studied. Absolute numbers were recalculated when percentages were reported. Furthermore, information on Hardy-Weinberg equilibrium (HWE) was collected or calculated manually if missing.

The literature search and data extraction were undertaken independently and blindly by two authors (PPH and YGC) using a standardized approach. Any discrepancies were resolved by consensus.

\section{Statistical analysis}

RevMan 5.0.24 software, developed by the Cochrane Collaboration (http://www.cc-ims.net/revman, accessed on June 16, 2010), was used for the meta-analysis. The HWE was assessed by the chi-square test for studies if needed. In general, the fixed-effects model was used in the absence of betweenstudy heterogeneity (the Cochran's Q and $\mathrm{I}^{2}$ statistics); otherwise the random-effects model was used. ${ }^{14}$ In this meta-analysis, we implemented the random-effects model only to coordinate the individual effect-size estimates because with a fixed-effects model, only sampling error contributes to the differences between the observed effect-size estimates across individual studies. ${ }^{15}$ In contrast, two sources of variance coexist in a random-effects model: the sample error and between-study heterogeneity. Given the ubiquitous nature of heterogeneity between studies, a random-effects model is appropriate.

In addition, sensitivity or subgroup analyses were conducted to seek more narrowly drawn subsets of the studies by removing an individual study each time or studies with similar features such as deviations from HWE to assess individual effects. Finally, we assessed publication bias using a funnel plot and the fail-safe number $\left(\mathrm{N}_{\mathrm{fs}}\right)$ with the significance set at 0.05 for each meta-comparison. If the calculated $\mathrm{N}_{\mathrm{fs}}$ value was smaller than the number of observed studies, the meta-analysis results might show risk of publication bias. We calculated the $\mathrm{N}_{\mathrm{fs} 0.05}$ according to the formula $\mathrm{N}_{\mathrm{fs} 0.05}=(\Sigma \mathrm{Z} / 1.64)^{2}-\mathrm{k}$ ( $\mathrm{k}$ is the number of articles included in the meta-analysis).

\section{Results}

\section{Study Characteristics}

The initial search with the electronic search strategy described above and manual search yielded 226 potential literature citations, of which 218 studies were excluded after scanning the titles and abstracts (Figure 1). The two authors searched the full articles for the remaining eight abstracts and excluded four articles (the full-text of one abstract was not available, two articles had insufficient data for analysis, and two articles used the same subjects ${ }^{11,12}$ ). Only four original articles ${ }^{9-}$ 11,13 satisfied our selection criteria and were included in the analysis, with $821 \mathrm{AD}$ patients and 1380 healthy controls. The interobserver agreement for the study selection was excellent $(\kappa$ $=0.92$ ). All these studies were full papers published in English from 2000 to 2010. According to the study design, the Kim et al study ${ }^{11}$ involved a population-based design, and the remaining three a hospital-based design. Of these four populations, two $(50 \%)$ were from mainland China, ${ }^{9,13}$ one $(25 \%)$ was from Japan, ${ }^{10}$ and one (25\%) was from South Korea. ${ }^{11}$

The detailed characteristics of the four eligible studies are listed in Table 1 . The percentages of $A L D H 2 * 2$ carriers in AD patients ranged from $25 \%$ to $71.3 \%$ and that in controls from $28.7 \%$ to $46 \%$. Except for the Kamino et al study ${ }^{10}$ ( $p=0.04$ for controls), the genotype distributions for both patients and controls were in HWE ( $\mathrm{p}>0.05)$. 


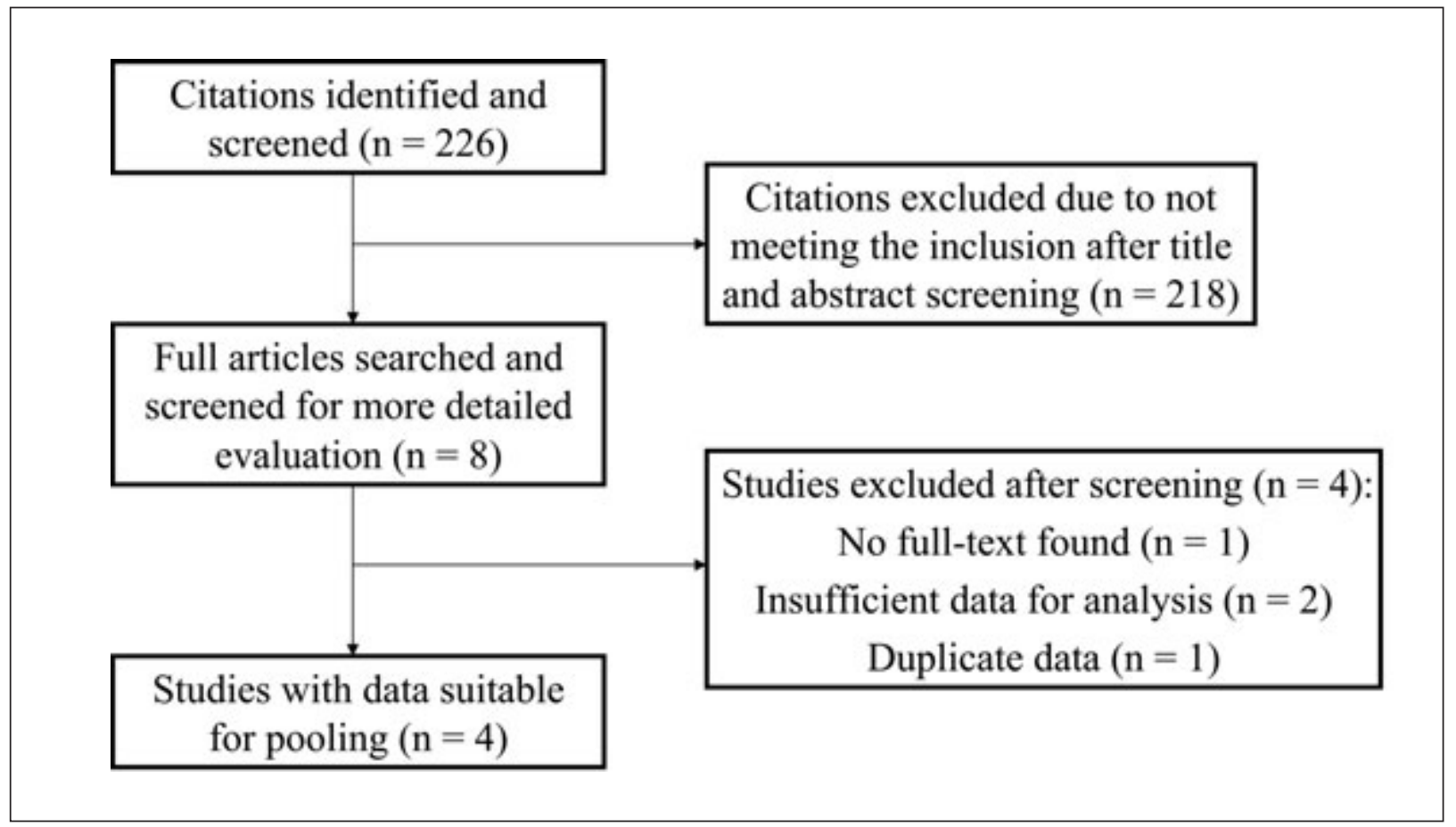

Figure 1: Flow chart of the systematic search process.

Table 1: Detailed characteristics of eligible studies

\begin{tabular}{|c|c|c|c|c|}
\hline Publication & Kamino et al. ${ }^{10}$ & Kim et al. ${ }^{11}$ & Wang et al. ${ }^{9}$ & Zhou et al. ${ }^{13}$ \\
\hline \multicolumn{5}{|c|}{ Sample size, $n$} \\
\hline Patients & 447 & 80 & 188 & 106 \\
\hline Controls & 447 & 610 & 223 & 100 \\
\hline \multicolumn{5}{|c|}{$A L D H 2 * 2$ carriers, $\mathrm{n}(\%)$} \\
\hline Patients & $215(48.1)$ & $20(25.0)$ & $134(71.3)$ & $41(38.7)$ \\
\hline Controls & $167(37.4)$ & $175(28.7)$ & $99(44.4)$ & $46(46.0)$ \\
\hline \multicolumn{5}{|c|}{$\mathrm{p}$ values for Hardy-Weinberg equilibrium test } \\
\hline Patients & 0.62 & 0.24 & 0.81 & 0.09 \\
\hline Controls & 0.04 & & 0.88 & 0.72 \\
\hline \multicolumn{5}{|c|}{ Age, mean (SD) years } \\
\hline Patients & $76.7(6.9)$ & $72.8(5.7)$ & $77.4(6.4)$ & $71.6(6.6)$ \\
\hline Controls & $77.1(7.2)$ & & $72.2(5.3)$ & $69.2(7.7)$ \\
\hline \multicolumn{5}{|c|}{ Sex, male/female } \\
\hline Patients & $123 / 324$ & $282 / 408$ & $92 / 96$ & $41 / 65$ \\
\hline Controls & $123 / 324$ & & $138 / 85$ & $41 / 59$ \\
\hline Study design & Hospital-based & Population-based & Hospital-based & Hospital-based \\
\hline Ethnicity & Japanese & South Koreans & Chinese & Chinese \\
\hline
\end{tabular}




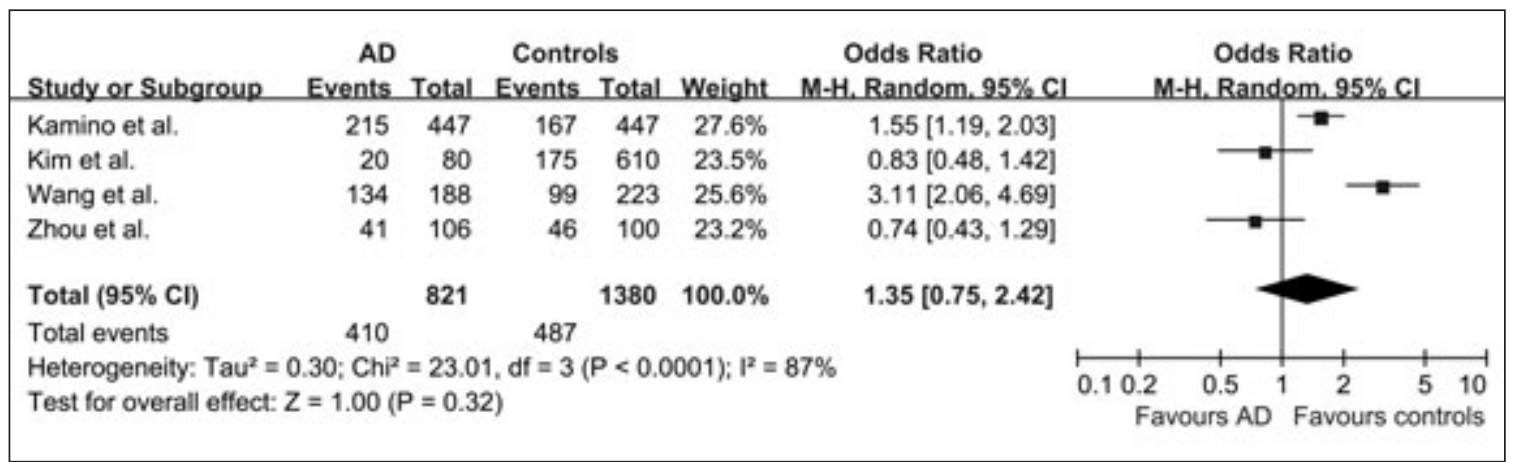

Figure 2: Random-effects odds ratio for the association of ALDH2 polymorphism with risk of Alzheimer's disease. The size of the black box is proportional to the weight of the corresponding study. The pooled estimate is displayed as a diamond. Bars, 95\% confidence interval.

\section{Main meta-analysis results}

Under the random-effects model, we found no association of $A L D H 2 * 2$ allele and increased $\mathrm{AD}$ risk $(\mathrm{OR}=1.35 ; 95 \% \mathrm{CI}=$ $0.75-2.42 ; \mathrm{p}=0.32$ ) (Figure 2). Nevertheless, of note, the initial studies for studies by Wang et $\mathrm{al}^{9}(\mathrm{OR}=3.11 ; 95 \% \mathrm{CI}=2.06-$ 4.69) and Kamino et $\mathrm{al}^{10}(\mathrm{OR}=1.55 ; 95 \% \mathrm{CI}=1.19-2.03)$ showed a significantly increased risk of $A L D H 2 * 2$ allele present versus $A L D H 2 * 2$ allele absent for susceptibility to $\mathrm{AD}$, whereas others consistently showed the opposite associations. Furthermore, the meta-analysis confirmed a significant association of presence of $A P O E \varepsilon 4$ and increased AD risk (OR $=2.98 ; 95 \% \mathrm{CI}=1.84-4.84 ; \mathrm{p}<0.00001)($ Figure 3$)$.

\section{Sensitivity/subgroup analyses}

In the study by Kamino et $\mathrm{al}^{10}, A L D H 2$ genotype frequencies in the control group deviated from HWE $(\mathrm{p}=0.04)$. The Kim et al study ${ }^{11}$ was population-based and HWE in either group was not assessed because of insufficient information for genotype counts. However, exclusion of each of the above two studies generated no materially changes for the pooled $\mathrm{ORs}(\mathrm{OR}=1.26$,
$95 \% \mathrm{CI}=0.47-3.33, \mathrm{p}=0.64 ; \mathrm{OR}=1.56,95 \% \mathrm{CI}=0.79-3.08$, $\mathrm{p}=0.20$, respectively).

Only two articles ${ }^{10,13}$ were available in the subgroup analysis by gender and three $9,10,13$ by $A P O E \varepsilon 4$ status. Results of subgroup analyses for the estimates are in Table 2 . The betweenstudy heterogeneity was explained in part by gender ratio. The subgroup analyses still revealed no significant association of $A L D H 2$ genotype and $\mathrm{AD}$ risk after adjustment for $A P O E \& 4$ status ( $\mathrm{p}=0.07$ for carriers and $\mathrm{p}=0.22$ for non-carriers); however, the association was significant for men after stratification by sex $(\mathrm{OR}=1.72 ; 95 \% \mathrm{CI}=1.10-2.67 ; \mathrm{p}=0.02)$.

\section{Publication bias}

The funnel plot assessing the publication bias of all four studies is shown in Figure 4. The plot shows a degree of asymmetry possibly consistent with "small study" bias. We calculated the $\mathrm{N}_{\text {fs } 0.05}$ for both $A L D H 2 * 2$ and $A P O E \& 4$ being present. The $\mathrm{N}_{\mathrm{fs} 0.05}$ values for both comparisons were greater than the number of studies included in the meta-analysis.

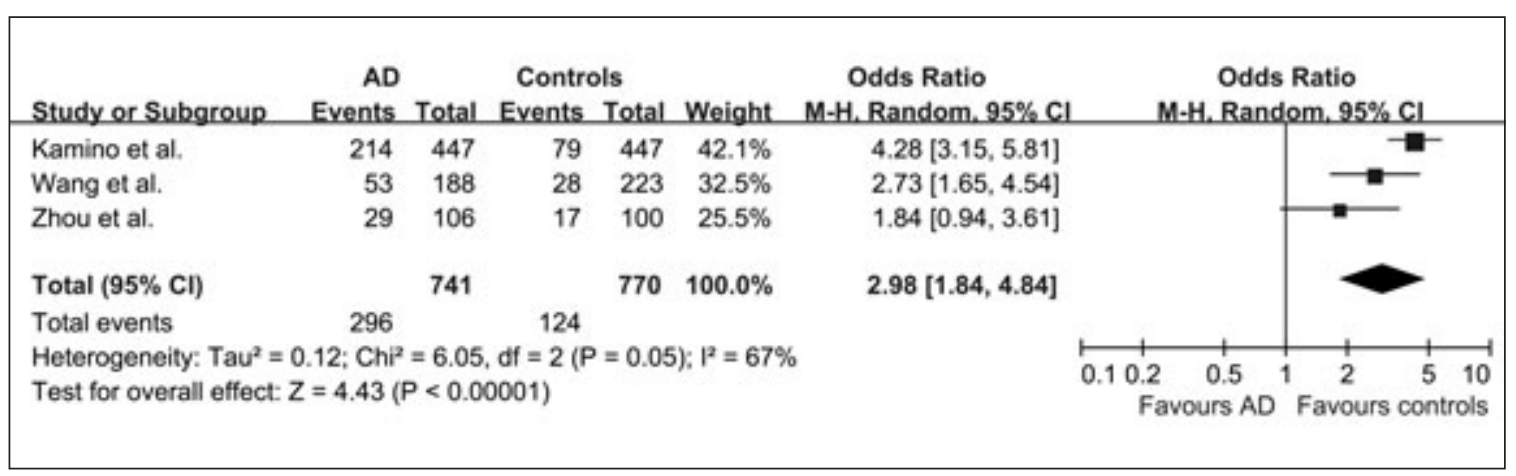

Figure 3: Random-effects odds ratio for the association of apolipoprotein E polymorphism with risk of Alzheimer's disease. The size of the black box is proportional to the weight of the corresponding study. The pooled estimate is displayed as a diamond. Bars, $95 \%$ confidence interval. 
Table 2: Subgroup analyses of association of $A L D H 2$ genotype and Alzheimer's disease

\begin{tabular}{lccccc}
\hline Category & Studies, $\mathrm{n}$ & References & AD, $\mathrm{n}$ & OR (95\% CI) & $\mathrm{p}^{\dagger}$ \\
\hline Adjustment by gender & 2 & & & & \\
$\quad$ Male & 2 & 10,13 & 163 & $1.72(1.10-2.67)$ & 0.02 \\
$\quad \begin{array}{l}\text { Female } \\
\text { Adjustment by APOE \&4 status }\end{array}$ & 3 & 10,13 & 390 & $0.91(0.33-2.49)$ & 0.86 \\
$\quad \begin{array}{l}\text { APOE \&4 carriers } \\
\text { APOE \&4 non-carriers }\end{array}$ & 3 & $9,10,13$ & 296 & $1.58(0.96-2.61)$ & 0.07 \\
\end{tabular}

AD: Alzheimer's disease; OR: odds ratio; CI: confidence interval; APOE $\varepsilon 4$ : apolipoprotein E epsilon 4 allele.

$\dagger$ The p-value of OR determined by the Z-test. Statistical significance was set at p-value 0.05 .

\section{Discussion}

To our knowledge, this is the first meta-analysis examining the association of $A L D H 2$ Glu504Lys polymorphism and AD in East Asians. In view of the inconsistencies of present results of studies regarding this association with $\mathrm{AD}$, our meta-analysis proved to be a more powerful approach in estimating the true effect size than a single study. Our stratified analyses suggested that a gender difference might account for the inconsistency of findings across studies, and we found a significant association of presence of $A L D H 2 * 2$ and $\mathrm{AD}$ risk in East Asian men. However, the association did not differ substantially by $A P O E \varepsilon 4$ status so was unlikely to have been affected by $A P O E \varepsilon 4$.
Previous studies ${ }^{16-18}$ have suggested that alcohol consumption might affect the development of AD by producing the neurotoxic substance acetaldehyde, which might alter neurons and transmitting molecules such as muscarinic cholinergic receptor and serotonin in the brain. Mitochondrial ALDH2 metabolizes acetaldehyde produced from ethanol into acetate. The $A L D H 2$ gene is the strongest genetic factor influencing alcohol drinking behavior and relates to the risk of alcoholism, because carriers of the $A L D H 2 * 2$ allele (rare in populations except Asians) have a low tolerance of alcohol. ${ }^{19-21}$ In addition, oxidative stress may underlie age-dependent memory loss and cognitive decline. A reactive intermediate

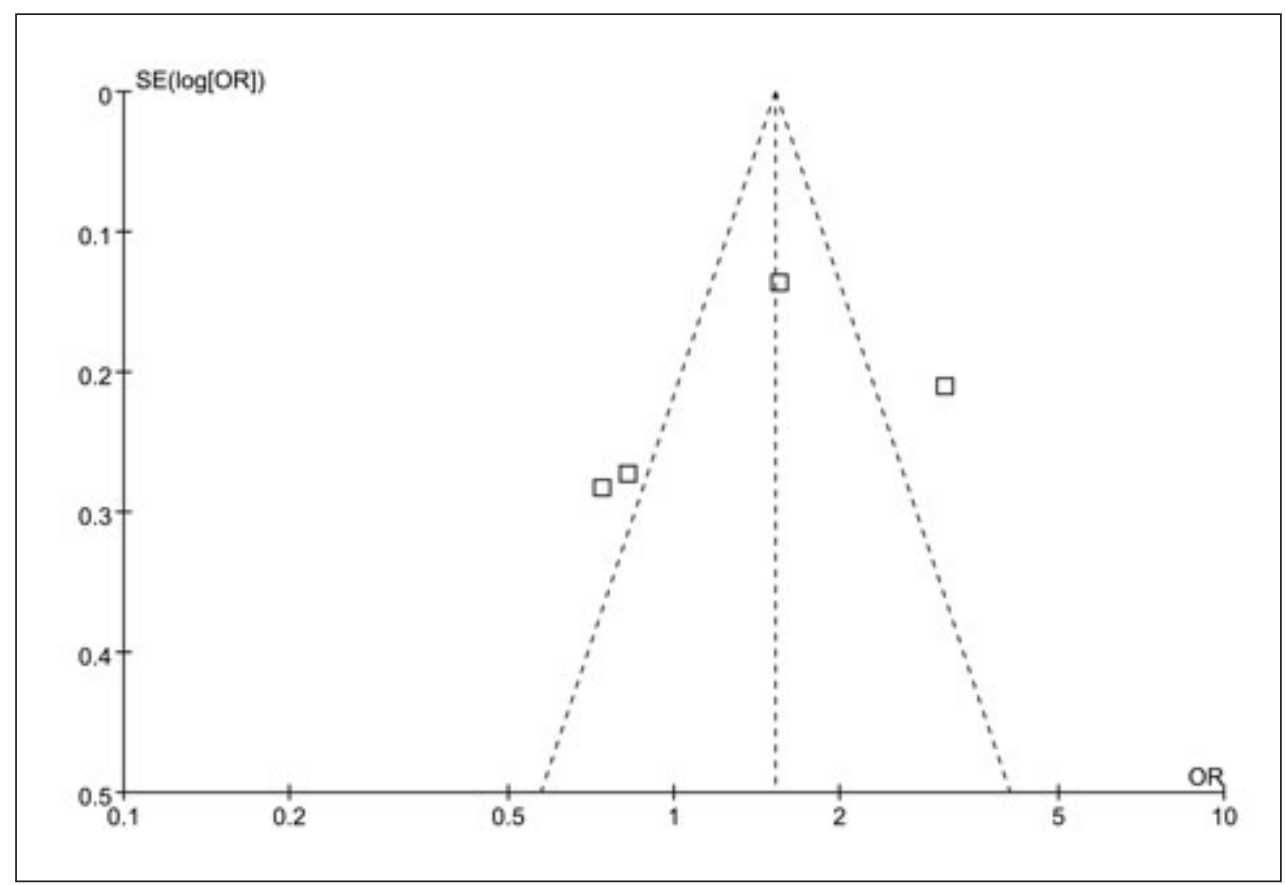

Figure 4: Funnel plot of publication bias for the association of ALDH2 polymorphism with risk of Alzheimer's disease. 
generated by lipid peroxidation, $\mathrm{HNE}$, is known to accumulate in the brain in neurodegenerative disease..$^{22}$ Ohsawa et $\mathrm{al}^{23}$ found that ALDH2 detoxifies HNE by oxidizing its aldehyde group, and transgenic mice with low ALDH2 activity exhibited an agedependent neurodegeneration accompanying memory loss. Furthermore, Bai et $\mathrm{al}^{24}$ found that overexpressed $A L D H 2$ gene might moderate HNE-induced neuronal death by regulating caspase- 3 protein and reactive oxygen species in cultured hippocampal neurons. Thus the $A L D H 2$ polymorphism may represent a desirable candidate for genetic risk factors for cognitive impairment and dementia among older East Asians. However, several small-sample investigations of the association of the mutant $A L D H 2$ genotype with $\mathrm{AD}$ in East Asians showed conflicting results. ${ }^{9-13}$

In most Asian countries, cultural norms and social and attitudinal factors lead to much more frequent alcohol abuse in men than women, ${ }^{25,26}$ which might be the main reason that East Asian men carrying the $A L D H 2 * 2$ allele were more likely to have subsequent $\mathrm{AD}$ diagnosis in our stratified analyses. Thus abstinence or mild drinking might be helpful to reduce the risk of cognitive impairment, dementia, and $\mathrm{AD}$ in this population. Evidence of behavioural and physiological interactions suggests that tobacco and alcohol use may not only individually affect AD, but may also modify each other's effects, with smoking reducing the risk of $\mathrm{AD}$ among drinkers. ${ }^{27}$

In a recent simulation study, ${ }^{28}$ case-control status was determined by two interacting polymorphisms with heritabilities ranging from 0.025 to 0.4 with replication sample sizes ranging from 400 to 1600 individuals. This study showed that the power to replicate the statistically significant independent main effect of one polymorphism could drop dramatically with a change of allele frequency of less than 0.1 at a second interacting polymorphism, and differences in allele frequency could result in a reversal of allelic effects whereby a protective allele becomes a risk factor in replication studies, which seems to be a possible explanation for divergent results between the present initial study and subsequent replication. It is thus reasonable to speculate that if involved, the impact of $A L D H 2$ polymorphism on AD might fail to replicate and should be checked for interactions with other polymorphisms, particularly when samples are collected from groups with distinct ethnic backgrounds or different geographic regions.

Although our sample size of more than 2000 subjects is not small, it may not be large enough to detect genes that contribute to $\mathrm{AD}$ through small effects. As well, ALDH2 Glu504Lys polymorphism might be linked to a causal variant or others within or near the $A L D H 2$ gene to produce the final disease phenotype. Therefore, conclusions are premature until a large, well-performed study confirms or refutes our results.

$A L D H 2 * 2$ is negatively associated with alcohol use. If people with a combination of alcohol use and dementia are underrepresented in clinical settings or if they are less likely to be classified as having $\mathrm{AD}$, then $A L D H 2 * 2$ frequencies may be exaggerated in clinical samples of AD patients as compared with controls. The $A L D H 2 * 2$ allele frequencies among the four Asian populations ranged from $15.7 \%$ to $35.3 \%$. If $A L D H 2 * 2$ is truly associated with $\mathrm{AD}$, the different frequencies of $A L D H 2 * 2$ among different populations might obscure the associations. Level of education can modulate the risk of dementia and may modify the effect of biological risk factors on incidence of AD. ${ }^{29,30}$ We were not sure of the educational levels of the four populations included in our analyses, but differences in educational attainment might underlie heterogeneous findings.

Meta-analysis, as a quantitative approach to combine results from similar studies, has earned a crucial position in providing useful information for evidence-based medicine and health care decision making. However, there are several possible limitations in a meta-analysis. Such as: (i) not all the relevant studies are included, which might limit the generalization of the results and lead to a biased result; and (ii) as no blinding measures are devised regarding the names of authors or journals, it is possible for the reviewers to be subjective. ${ }^{31}$ Although two authors (PPH and YGC) independently and blindly searched and selected as many relevant articles as possible via four databases, our metaanalysis contains some inevitable limitations. First, the crosssectional nature of our included studies precludes comments on causality. Second, we could not retrieve information for various confounding factors considered effective modulators for the development of $\mathrm{AD}$ and should be considered in the analyses. This analysis did not consider alcohol-related histories and the educational levels of the subjects, which might mediate or modify the association. To our knowledge, only the study by Kim et $\mathrm{al}^{11}$ took into account alcohol consumption, and no significant association was found between $A L D H 2$ genotype and $\mathrm{AD}$ in either drinkers $(\mathrm{OR}=0.39 ; 95 \% \mathrm{CI}=0.05-3.07 ; \mathrm{p}=0.37)$ or nondrinkers $(\mathrm{OR}=0.83 ; 95 \% \mathrm{CI}=0.47-1.46 ; \mathrm{p}=0.51)$. Finally, we focused only on $A L D H 2$ Glu504Lys polymorphism and did not evaluate other single-nucleotide polymorphisms in $A L D H 2$. The potential role of Glu504Lys polymorphism may be diluted or masked by other gene-gene or gene-environment interactions.

\section{Conclusions}

In summary, our study expands the previous findings of $\mathrm{AD}$ by showing no significant association of presence of $A L D H 2 * 2$ and increased risk of $\mathrm{AD}$ in East Asians, either before or after stratification for $A P O E \& 4$ status. However, among East Asian men, $A L D H 2 \mathrm{GA} / \mathrm{AA}$ genotype increases AD risk, although the effect size is moderate. Additional cross-sectional or longitudinal studies with large sample sizes and in different populations examining gene-gene or gene-environment interactions, as well as studies seeking to provide biological or clinical validations of our results, are warranted.

\section{ACKNOWLEDGMENTS}

This study was supported by the National 973 Basic Research Program of China (No.2009CB521904 and No.2010CB732605), by the Department of Science and Technology of Shandong Province, China (No.Y2007C075 and No.2008RKB060), by a grant for Excellent Medical Subject Leaders from the Health Department of Shandong Province in China, and by the Cultivation Fund of the Key Scientific and Technical Innovation Project, Ministry of Education of China. 


\section{REFERENCES}

1. Blacker D, Haines JL, Rodes L, et al. ApoE-4 and age at onset of Alzheimer's disease: the NIMH genetics initiative. Neurology. 1997;48(1):139-47.

2. Hosoda A, Inoue T, Mao CC, et al. Polymorphisms in the human apolipoprotein $\mathrm{E}$ receptor 2 gene in Japanese sporadic Alzheimer's disease patients. Biosci Biotechnol Biochem. 2010: 74(3):677-9.

3. Ohta S, Ohsawa I. Dysfunction of mitochondria and oxidative stress in the pathogenesis of Alzheimer's disease: on defects in the cytochrome c oxidase complex and aldehyde detoxification. J Alzheimer's Dis. 2006;9(2):155-66.

4. Tanzi RE, Bertram L. New frontiers in Alzheimer's disease genetics. Neuron. 2001;32(2):181-4.

5. Picklo MJ, Olson SJ, Markesbery WR, Montine TJ. Expression and activities of aldo-keto oxidoreductases in Alzheimer disease. J Neuropathol Exp Neurol. 2001;60(7):686-95.

6. Chen CH, Budas GR, Churchill EN, Disatnik MH, Hurley TD, Mochly-Rosen D. Activation of aldehyde dehydrogenase-2 reduces ischemic damage to the heart. Science. 2008;321(5895): 1493-5.

7. Li Y, Zhang D, Jin W, et al. Mitochondrial aldehyde dehydrogenase2 (ALDH2) Glu504Lys polymorphism contributes to the variation in efficacy of sublingual nitroglycerin. J Clin Invest. 2006;116(2):506-11.

8. Michel TM, Gsell W, Käsbauer L, et al. Increased activity of mitochondrial aldehyde dehydrogenase (ALDH) in the putamen of individuals with Alzheimer's disease: a human postmortem study. J Alzheimers Dis. 2010;19(4):1295-301.

9. Wang B, Wang J, Zhou S, et al. The association of mitochondrial aldehyde dehydrogenase gene $(\mathrm{ALDH} 2)$ polymorphism with susceptibility to late-onset Alzheimer's disease in Chinese. J Neurol Sci. 2008;268(1-2):172-5.

10. Kamino $K$, Nagasaka $K$, Imagawa $M$, et al. Deficiency in mitochondrial aldehyde dehydrogenase increases the risk for late-onset Alzheimer's disease in the Japanese population. Biochem Biophys Res Commun. 2000;273(1):192-6.

11. Kim JM, Stewart R, Shin IS, Jung JS, Yoon JS. Assessment of association between mitochondrial aldehyde dehydrogenase polymorphism and Alzheimer's disease in an older Korean population. Neurobiol Aging. 2004;25(3):295-301.

12. Shin IS, Stewart R, Kim JM, et al. Mitochondrial aldehyde dehydrogenase polymorphism is not associated with incidence of Alzheimer's disease. Int J Geriatr Psychiatry. 2005;20(11): 1075-80.

13. Zhou S, Huriletemuer, Wang J, et al. Absence of association on aldehyde dehydrogenase $2(\mathrm{ALDH} 2)$ polymorphism with Mongolian Alzheimer patients. Neurosci Lett. 2010;468(3): 312-15.

14. Higgins JP, Thompson SG, Deeks JJ, Altman DG. Measuring inconsistency in meta-analyses. BMJ. 2003;327(7414):557-60.

15. Cohn LD, Becker BJ. How meta-analysis increases statistical power. Psychol Methods. 2003;8(3):243-53.
16. Butterworth RF. Pathophysiology of alcoholic brain damage: synergistic effects of ethanol, thiamine deficiency and alcoholic liver disease. Metab Brain Dis. 1995;10(1):1-8.

17. Freund G, Ballinger WE Jr. Alzheimer's disease and alcoholism: possible interactions. Alcohol. 1992;9(3):233-40.

18. Mann K, Widmann U. The neurobiology of alcoholism. Neuropathology and CT/NMR findings. Fortschr Neurol Psychiatr. 1995;63(6):238-47.

19. Goedde HW, Agarwal DP, Harada S, et al. Population genetic studies on aldehyde dehydrogenase isozyme deficiency and alcohol sensitivity. Am J Hum Genet. 1983;35(4):769-72.

20. Stewart MJ, Malek K, Crabb DW. Distribution of messenger RNAs for aldehyde dehydrogenase 1 , aldehyde dehydrogenase 2 , and aldehyde dehydrogenase 5 in human tissues. J Investig Med. 1996;44(2):42-6.

21. Tan EC, Lim L, Leong JY, et al. Alcohol and aldehyde dehydrogenase polymorphisms in Chinese and Indian populations. Subst Use Misuse. 2010;45(1-2):1-14.

22. Butterfield DA, Bader Lange ML, Sultana R. Involvements of the lipid peroxidation product, $\mathrm{HNE}$, in the pathogenesis and progression of Alzheimer's disease. Biochim Biophys Acta. 2010;1801(8):924-9.

23. Ohsawa I, Nishimaki K, Murakami Y, Suzuki Y, Ishikawa M, Ohta S. Age-dependent neurodegeneration accompanying memory loss in transgenic mice defective in mitochondrial aldehyde dehydrogenase 2 activity. J Neurosci. 2008;28(24):6239-49.

24. Bai J, Mei Y. Overexpression of aldehyde dehydrogenase-2 attenuates neurotoxicity induced by 4-hydroxynonenal in cultured primary hippocampal neurons. 2010 Apr 2. [Epub ahead of print].

25. Olafsdóttir H, Raitasalo K, Greenfield TK, Allamani A. Concern about family members' drinking and cultural consistency: a Multi-Country GENACIS Study. Contemp Drug Probl. 2009;36 (1): 1 .

26. Perera B, Fonseka P, Ekanayake R, Lelwala E. Smoking in adults in Sri Lanka: prevalence and attitudes. Asia Pac J Public Health. 2005;17(1):40-5

27. Tyas SL, Koval JJ, Pederson LL. Does an interaction between smoking and drinking influence the risk of Alzheimer's disease? Results from three Canadian data sets. Stat Med. 2000;19(1112): $1685-96$.

28. Greene CS, Penrod NM, Williams SM, Moore JH. Failure to replicate a genetic association may provide important clues about genetic architecture. PLoS One. 2009;4(6):e5639.

29. Chen JH, Lin KP, Chen YC. Risk factors for dementia. J Formos Med Assoc. 2009;108(10):754-64.

30. Stern Y, Gurland B, Tatemichi TK, Tang MX, Wilder D, Mayeux R. Influence of education and occupation on the incidence of Alzheimer's disease. JAMA. 1994;271(13):1004-10.

31. Wen J, Ren Y, Wang L, et al. The reporting quality of meta-analyses improves: a random sampling study. J Clin Epidemiol. 2008;61 (8):770-5. 